\title{
Influence of the compression ratio on the performance and emission characteristics of a vcr diesel engine fuelled with alcohol blended fuels ${ }^{\S}$
}

\author{
Hasan Serin ${ }^{1 *}$, Şafak Yıldızhan² \\ 1,2Department of Automotive Engineering, Çukurova University, Turkey
}

\begin{abstract}
The present study is an experimental study that investigates the performance and emission characteristics of a variable compression ratio (VCR) diesel engine when the engine is fuelled with diesel, biodiesel, and small amount of alcohol blended fuels. The experimental study was evaluated with a single cylinder, water cooled, multi fuel VCR diesel test engine. The experimental results showed that increasing compression ratio improves performance characteristics such as brake thermal efficiency and specific fuel consumption of the test engine for all test fuels. However, increasing compression ratio caused to increase of $\mathrm{NO}_{\mathrm{x}}$ and $\mathrm{CO}_{2}$ emissions. Blending alcohol with diesel fuel showed a slight decrement in the means of brake thermal efficiency and thus elevated specific fuel consumption values. The maximum increment of specific fuel consumption was measured as $0,34 \%$ for diesel-alcohol blends. But, blending alcohols with biodiesel fuel improved performance characteristics of the engine compared to diesel fuel up to $2,65 \%$. Blending biodiesel with alcohols showed improvement in the means of $\mathrm{NO}_{\mathrm{x}}$ emissions up to $6,01 \%$.
\end{abstract}

Keywords: Compression ratio, Alcohol, Biodiesel, Performance, Emission.

\section{INTRODUCTION}

The high cost and the hazard of the running out of fossil fuels, also the narrowing range of environmental legislations force researchers to investigate more eco-friendly, low cost and renewable energy sources [1,2]. Biofuel usage is increasing day by day tremendously. The advantages of biofuels such as being renewable and biodegradable make biofuels more favourable compared to fossil fuel. However, biofuels have some drawbacks such as lower energy density and higher cost presently [3-5].

Biodiesel is one of the promising biofuels which is widely used and has been investigated by many researchers. Biodiesel has many advantages such as high oxygen content and being absence of sulphur, besides the having the advantages of being biofuel. But in contrary, biodiesel usage causes to increase of NOx emissions and slightly increases specific fuel consumption [6-8]. One of the biofuel alternatives is alcohol usage as energy source. Alcohols (methanol, ethanol, butanol, propyl alcohol etc.) seem to be a good alternative for spark ignition engines and a promising additive for diesel engines. Alcohols are mostly produced by fermentation and distillation of corns and sugar canes, and starch crops. Also, wood, garbage, biomass, natural gas and coal can be used for alcohol production with different methods [9] .

Alcohols such as methanol and ethanol has the advantage of high octane rating, extra oxygen content, and lower carbon-hydrogen ratio compared to fossil based fuels. Alcohol usage as additive for biodiesel can improve the one of the most significant drawbacks of biodiesel usage which is relatively very higher rate of NOx emission caused by higher combustion temperature of biodiesels. Alcohols have high vaporization heat which cools the air introducing the cylinder and thus decrease the end-cylinder temperature. Also cooling effect of the alcohol improves the volumetric efficiency of the engine and provides better brake thermal efficiency [10-12].

Several investigations have been made by many researchers on the use of alcohols as fuel additives in spark ignition and compression ignition engines [13-16]. Tosun et al., (2014) investigated the effects of different alcohols such as methanol, ethanol, and butanol on the performance and emission characteristics of a diesel engine when the alcohols are blended with peanut biodiesel [7]. The study showed that, alcohol addition to peanut methyl ester improved performance and combustion characteristics of the engine compared to peanut methyl ester. According to study, alcohol-biodiesel blends showed up to $20,53 \%$ reduction in the means of the CO emissions. Lattimore et al., (2016) investigated the effects of

\footnotetext{
${ }^{*}$ Corresponding authour

Email: hserin@cu.edu.tr (H. Serin)

$\S$ This paper was presented in the IMSEC-2016
} 
compression ratio and fuel characteristics on combustion and particulate matter emissions in a single cylinder gasoline engine [17]. The authors revealed that, addition ethanol or butanol decreases the combustion duration. The study also showed that, blending gasoline with butanol improves particulate matter and blending with ethanol improves NOx emissions.

\section{MATERIAL AND METHOD}

\subsection{Experimental Fuels}

The experimental study was conducted in Petroleum Research and Automotive Engineering Laboratories of the Department of Automotive Engineering at Çukurova University. False flax oil (Camelina Sativa) was used as raw material for biodiesel production. False flax methyl ester (FFME) was produced via the transesterification method. The reaction was performed with methyl alcohol in the presence of a catalyst $(\mathrm{NaOH})$. The metoxide was obtained before the reaction by reaction methyl alcohol and $\mathrm{NaOH}$. The reaction was evaluated in a spherical glass reactor equipped with reflux condenser, stirrer and thermometer. The reaction were performed with, methanol $20 \mathrm{wt} \%$, sodium hydroxide $0.5 \mathrm{wt} \%$. After the obtaining metoxide, the crude false flax samples and metoxide were mixed in the reactor. The mixture was heated up to $65^{\circ} \mathrm{C}$ and kept at this temperature for 90 minutes by stirring. After the reaction period, the crude methyl ester was waited at separating funnel for 8 hours. And then, crude glycerine was separated from methyl ester. Finally, the crude methyl ester was washed by warm water until the washed water became clear and dried at $105{ }^{\circ} \mathrm{C}$ for 1 hour. Finally washed and dried methyl ester was passed through a filter. At the end of the transesterification reaction $97 \%$ conversion of oil was obtained. Flow diagram of biodiesel production process is shown in Figure 1.

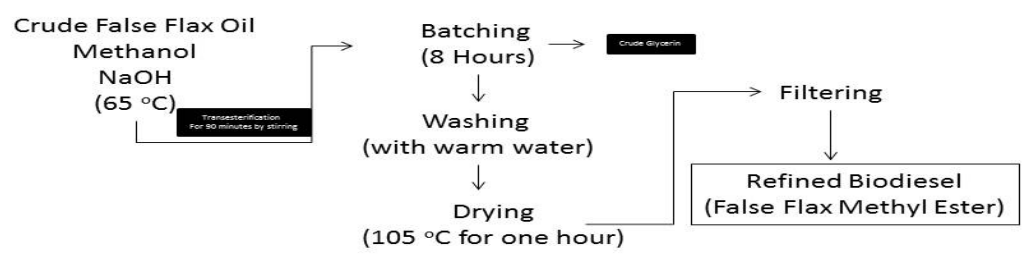

Figure 1: Biodiesel production flow diagram

Table 1 Test fuels

\begin{tabular}{|c|c|c|}
\hline Fuel & Composition & Test Fuel \\
\hline Low Sulphur Diesel & $100 \%$ Diesel & D \\
\hline False Flax Biodiesel & $100 \%$ FFME & B \\
\hline Diesel-Methanol & $95 \%$ Diesel $+5 \%$ Methanol & DM \\
\hline Diesel-Ethanol & $95 \%$ Diesel $+5 \%$ Ethanol & DE \\
\hline Diesel-Butanol & $95 \%$ Diesel $+5 \%$ Butanol & $\mathrm{DBu}$ \\
\hline Biodiesel-Methanol & $95 \%$ FFME $+5 \%$ Methanol & $\mathrm{BM}$ \\
\hline Biodiesel -Ethanol & $95 \%$ FFME $+5 \%$ Ethanol & $\mathrm{BE}$ \\
\hline Biodiesel -Butanol & $95 \%$ FFME $+5 \%$ Butanol & $\mathrm{BBu}$ \\
\hline
\end{tabular}

In the study, low sulphur diesel fuel (conventional diesel), false flax biodiesel (false flax methyl ester), diesel-alcohol, and biodiesel-alcohol blends were investigated in the means of performance and emission characteristics. In the study, three different alcohols which are Methanol $\left(\mathrm{CH}_{3} \mathrm{OH}\right)$, Ethanol $\left(\mathrm{C}_{2} \mathrm{H}_{5} \mathrm{OH}\right)$, and Butanol $\left(\mathrm{C}_{4} \mathrm{H}_{9} \mathrm{OH}\right)$ were used. The alcohols were blended with diesel fuel and biodiesel fuel. The test fuels were given in Table 1. Also some psychical properties of alcohols used in the study were given in Table 2.

Table 2 Psychical properties of alcohols used in the study

\begin{tabular}{|c|c|c|c|c|}
\hline Specification & Unit & $\begin{array}{c}\text { Methanol } \\
(\mathrm{CH} 3 \mathrm{OH})\end{array}$ & $\begin{array}{c}\text { Ethanol } \\
(\mathrm{C} 2 \mathrm{H} 5 \mathrm{OH})\end{array}$ & $\begin{array}{c}\text { Butanol } \\
(\mathbf{C 4 H 9 O H})\end{array}$ \\
\hline Purity (GC) & $\%$ & $>=99,8$ & $>=99.0$ & $>=99,8$ \\
\hline Density (20 oC) & $\mathrm{gr} / \mathrm{cm} 3$ & $0,791-0,793$ & $0,791-0,793$ & 0,810 \\
\hline Melting Point & $\mathrm{oC}$ & $-97,6$ & -116 & -89 \\
\hline Viscosity Dynamical $(20 \mathrm{oC})$ & $\mathrm{m}$. Pa.s & 0,545 & 1,2 & 2,57 \\
\hline Molar Mass & gr/mol & 32,04 & 32,04 & 74,12 \\
\hline Water & (K.F.) & $<=0,1$ & $<=0,5$ & $<=0,5$ \\
\hline
\end{tabular}

The psychical properties of the test fuels were measured before testing them in the test engine. Instruments used for analysing the products were; Zeltex ZX 440 NIR petroleum analyser with an accuracy of \pm 0.5 for determining cetane 
number; Tanaka AFP-102 for cold filter plugging point; Tanaka AKV-202 Auto Kinematic Viscosity test for determining the viscosity; Kyoto electronics DA-130 for density measurement, Tanaka flash point control unit FC-7 for flash point determination and IKA Werke C2000 bomb calorimeter for determination of heating value. The fuel quality measurements were performed according to EN 14214 and EN 590.

\subsection{Test Rig}

In the study, a single cylinder, water cooled, multi fuel, variable compression ratio (VCR) diesel engine and an eddy current dynamometer was used in order to evaluate the performance and emission characteristics of the fuels. All of the experiments were conducted under partial load (60\%) conditions due to full load operating conditions deteriorate the accuracy of the experiments since the too vibrant operating of the single cylinder engines. The experiments were evaluated at three different compression ratios (12:1, 14:1 and 16:1). Before the experiments the test engine was run for 15 minutes to achieve the stable operating conditions. The exhaust emission characteristics of the engine were also measured simultaneously. Table 3 and 4 shows the technical specifications of the engine test rig and the exhaust emission measurement device. Figure 2 demonstrates the schematic representation of experimental procedure.

Table 3 Technical specifications of the test engine and emission device

\begin{tabular}{|c|c|c|c|}
\hline Brand & Kirloskar Oil Engines & Brand & MRU Air Delta $1600 \mathrm{~V}$ \\
\hline Model & 240 & $\mathrm{CO}$ & $0-10 \%$ \\
\hline Configuration & Single Cylinder & $\mathrm{CO} 2$ & $0-20 \%$ \\
\hline Type & Four Stroke, Water Cooled & $\mathrm{HC}$ & $0-20000 \mathrm{ppm}$ \\
\hline Displacement & $661 \mathrm{cc}$ & $\mathrm{O} 2$ & $0-22 \%$ \\
\hline Bore & $87.5 \mathrm{~mm}$ & $\mathrm{NO}$ & $0-4000$ ppm \\
\hline Stroke & $110 \mathrm{~mm}$ & $\mathrm{NO} 2$ & $0-1000 \mathrm{ppm}$ \\
\hline $\begin{array}{l}\text { Maximum/Minimum Opera- } \\
\text { ting Speed }\end{array}$ & $2000 / 1200 \mathrm{rpm}$ & Lambda & $0-9.99$ \\
\hline Power & 3.5 Kw@1500 rpm & Accuracy & According to OIML-class 1 \\
\hline $\mathrm{CR}$ range & $12: 1-18: 1$ & Ambient Temperature & $+5 o-+45 o C$ \\
\hline Injection Variation & 0-25 Deg BTDC & Exhaust Gas Temperature & Max 650 oC \\
\hline Peak Pressure & $77.5 \mathrm{~kg} / \mathrm{cm} 2$ & & \\
\hline Air cleaner & Paper element type & & \\
\hline Weight & $160 \mathrm{~kg}$ & & \\
\hline Combustion Principle & Compression Ignition & & \\
\hline Lubricating System & Forced Feed System & & \\
\hline
\end{tabular}

\section{RESULTS AND DISCUSSIONS}

\subsection{Fuel Properties}

Fuel properties of low sulphur diesel, false flax oil methyl ester, and their blends with various alcohols were given in table 4. It can be seen from the fuel property test results diesel and biodiesel fuels used in the study were within the diesel and biodiesel standards. Alcohol addition to both diesel and biodiesel fuels decreased slightly the density values due to lower density of alcohols. Also, lower heating values of diesel-alcohol and biodiesel-alcohol blends were lower than diesel and biodiesel fuels. Blending alcohol resulted in with lower viscosity which can cause fuel pump plugs for both diesel and biodiesel fuels. Since the blend ratio was a small amount, psychical properties of test fuels were not significantly different compared to diesel and biodiesel fuels.

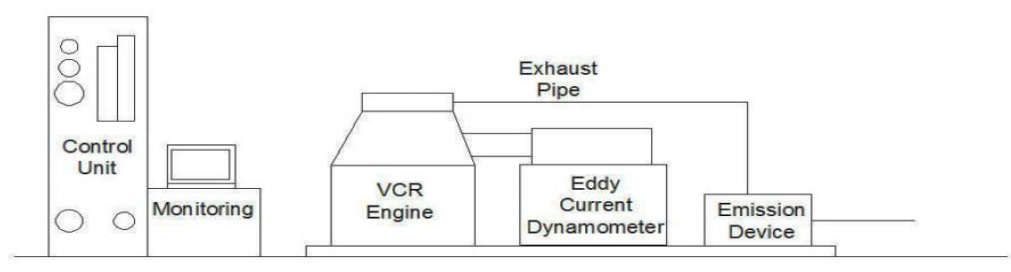

Figure 2: Schematic representation of the experimental test rig 
Table 4 Fuel properties of test fuels

\begin{tabular}{|c|c|c|c|c|c|c|c|c|c|c|}
\hline & \multicolumn{10}{|c|}{ Test Fuels } \\
\hline $\begin{array}{c}\text { Fuel } \\
\text { Properties }\end{array}$ & $\mathrm{D}$ & EN590 & B & EN 14214 & DM & $\mathrm{DE}$ & $\mathrm{DBu}$ & $\mathrm{BM}$ & $\mathrm{BE}$ & $\mathrm{BBu}$ \\
\hline Density $(20$ oC) $\mathrm{kg} / \mathrm{m} 3$ & 837 & $820-845$ & 883 & $860-900$ & 831 & 832 & 834 & 879 & 879 & 880 \\
\hline Cetane Number & 59,47 & Min 51 & 51,62 & Min 51 & 56,5 & 57,2 & 58,1 & 49,45 & 50,16 & 50,75 \\
\hline CFPP oC & -11 & - & -8 & $\begin{array}{c}\text { Summer }<4 \\
\text { Winter }<1\end{array}$ & -11 & -11 & -12 & -8 & -8 & -10 \\
\hline Heating Value, MJ/kg & $45 .-, 85$ & - & 38,22 & - & 44,55 & 44,99 & 45,21 & 37,29 & 37,74 & 37,96 \\
\hline $\begin{array}{l}\text { Kinematic Viscosity } \\
(40 \mathrm{oC}) \mathrm{mm} 2 / \mathrm{s}\end{array}$ & 2,76 & $2,0-4,5$ & 4,29 & $3.5-5.0$ & 2,68 & 2,71 & 2,75 & 4,07 & 4,12 & 4,21 \\
\hline Flash Point oC & 79.5 & Min 55 & $>120$ & Min 120 & - & - & - & - & - & - \\
\hline
\end{tabular}

\subsection{Performance Characteristics}

Figure 3 shows the brake thermal efficiency (BTHE) results of the experiments of test fuels at different compression ratios. Brake thermal efficiency can be defined as the ratio of heat input to power output of the engine. It can be seen clearly from the graph that the increasing CR improves BTHE values of all test fuels since the higher CR improves the combustion characteristics of the engine. The experiments revealed that alcohol addition to diesel fuel slightly reduced BTHE compared to diesel fuel due to lower calorific value of the alcohols [18]. The maximum decrement of BTHE was occurred with B95M5 fuel. But, alcohol addition to biodiesel fuel improved BTHE slightly. This improvement may be due to extra oxygen content of alcohol. With the increment of compression ratio specific fuel consumption (SFC) were improved due to higher BTHE and better combustion for all test fuels [10]. Diesel-alcohol blends showed slight increment in the means of SFC (Figure 4) compared to diesel fuel. The improvement in the means of combustion at higher compression ratios showed higher exhaust gas temperature (Figure 5).

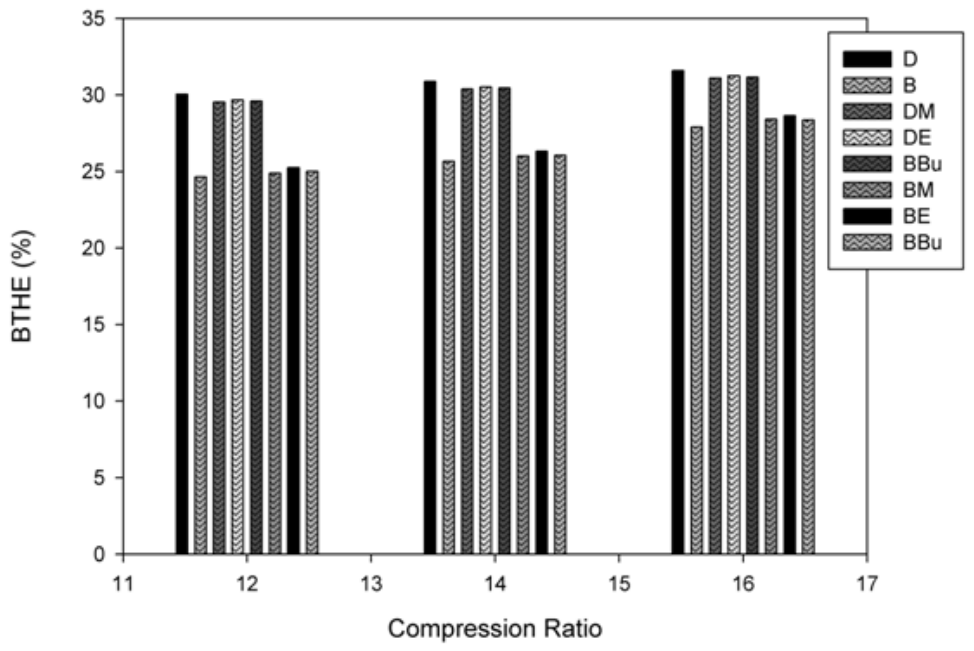

Figure 3: BTHE values of test fuels

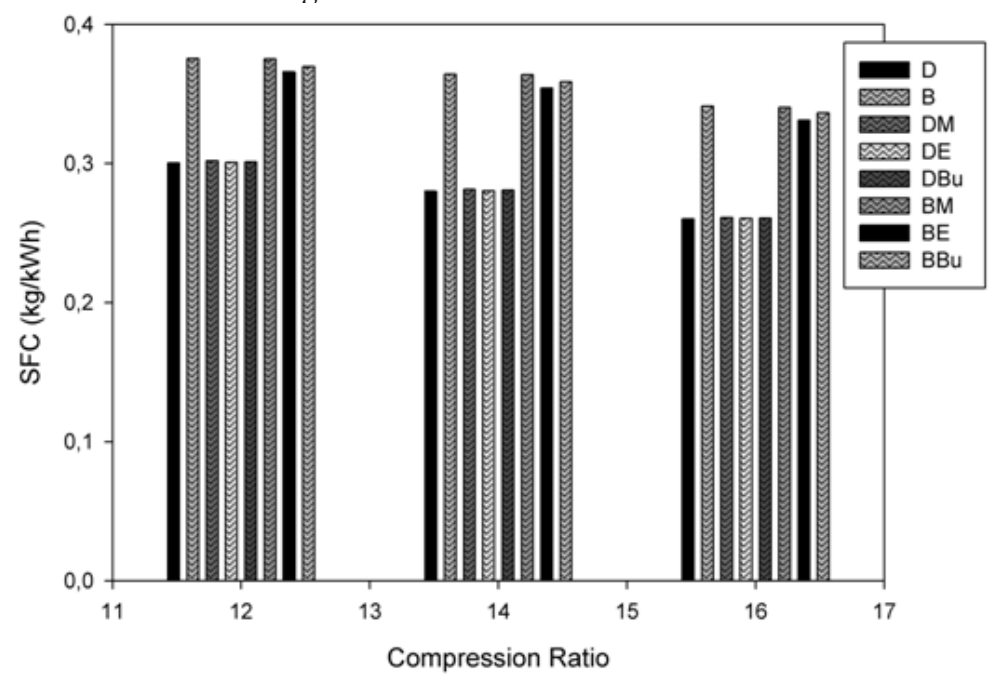

Figure 4: SFC values of test fuels 


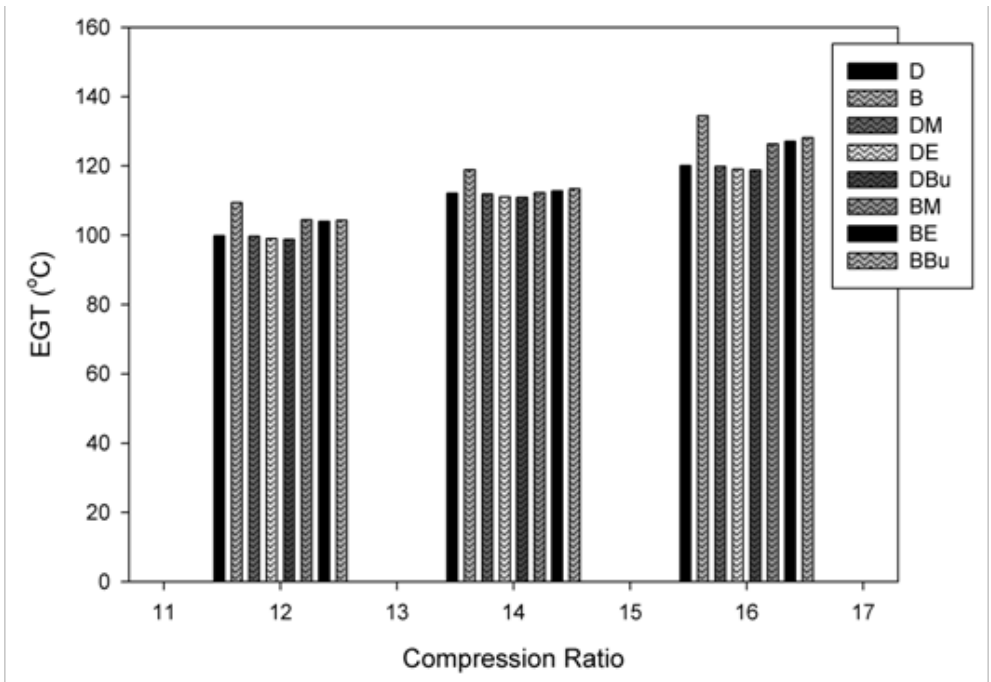

Figure 5: EGT values of test fuels

Diesel-alcohol blends showed a slight decrement in the means of BTHE and a slight increment of SFC. The maximum decrement of BTHE and the maximum increment of SFC was observed as 1,59\% and 0,34\%, respectively, compared to diesel fuel when the engine was fuelled with D95M5 fuel at 16:1 CR. But, blending biodiesel with alcohols showed the reverse trend of diesel-alcohol blends. The maximum improvement of BTHE for biodiesel-alcohol blends was obtained as 2,65\% when B95E5 fuel used compared to biodiesel fuel. And thus, B95E5 fuel usage resulted in 2,98\% improvement of SFC values.

\subsection{Emission Characteristics}

Figure 6,7,8 show the carbon monoxide $(\mathrm{CO})$, carbon dioxide $\left(\mathrm{CO}_{2}\right)$, and nitrogen oxides $(\mathrm{NOx})$ emissions of the test fuels, respectively. The experiments revealed that increasing compression ratio decreases $\mathrm{CO}$ emissions due to better combustion for all test fuels but increment of compression ratio causes to increment of $\mathrm{CO}_{2}$ and $\mathrm{NOx}$ emissions. At higher compression ratios, the more complete combustion occurs and thus, carbon molecules are mostly converted to $\mathrm{CO}_{2}$ instead of $\mathrm{CO}$ and unburned hydrocarbons (UHC) emissions. Also, the better combustion means higher in-cylinder temperature which is the main reason of NOx formation. So, increasing CR caused to increase of NOx emissions for all test fuels.

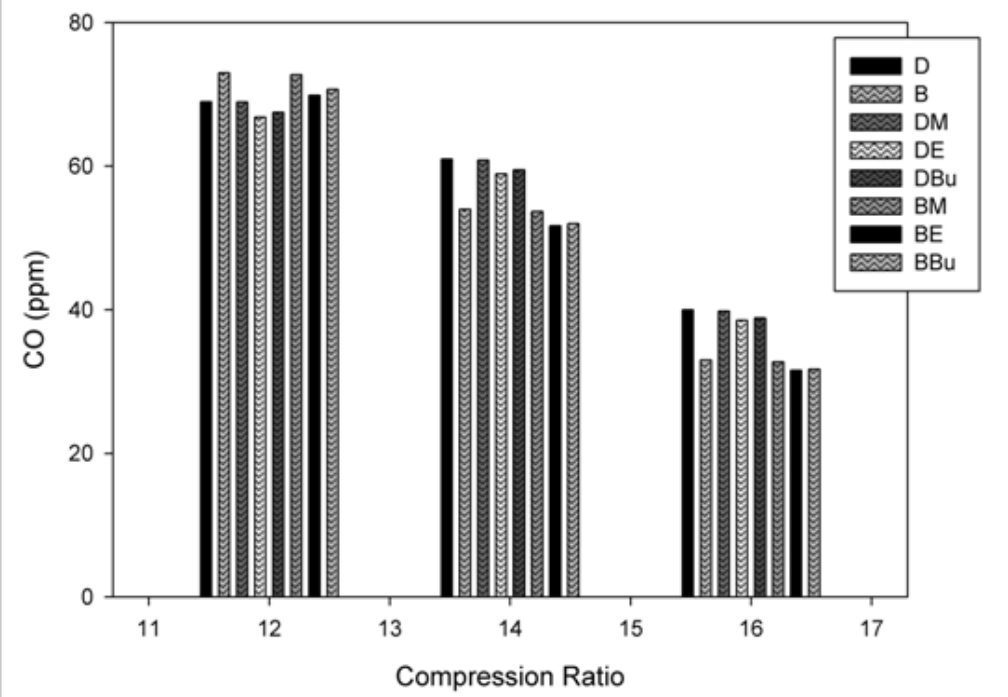

Figure 6: $\mathrm{CO}$ values of test fuels 


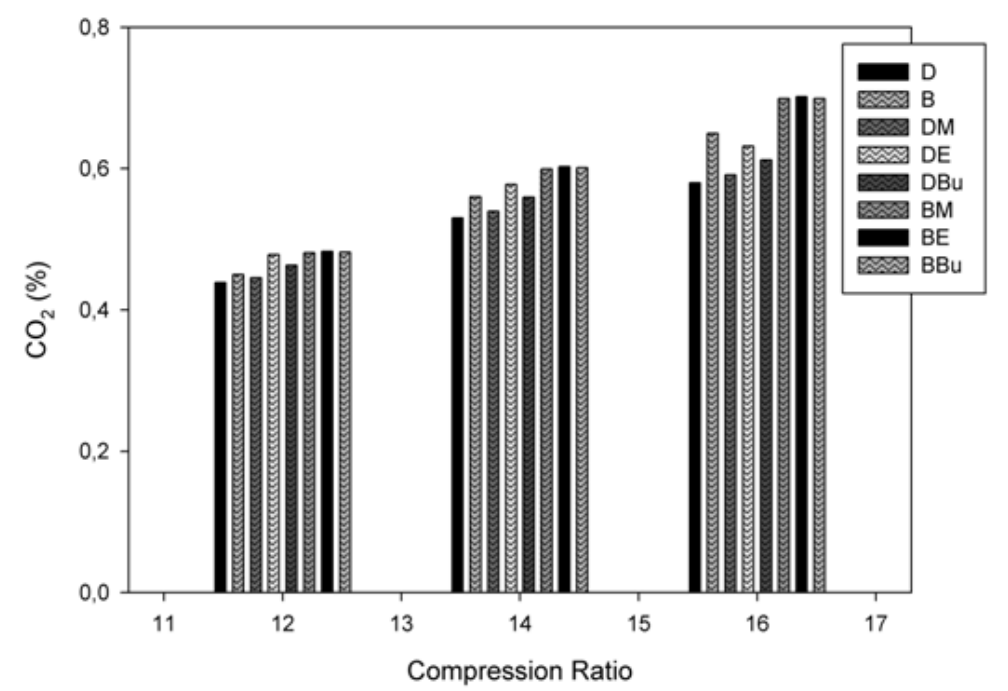

Figure 7: $\mathrm{CO}_{2}$ values of test fuels

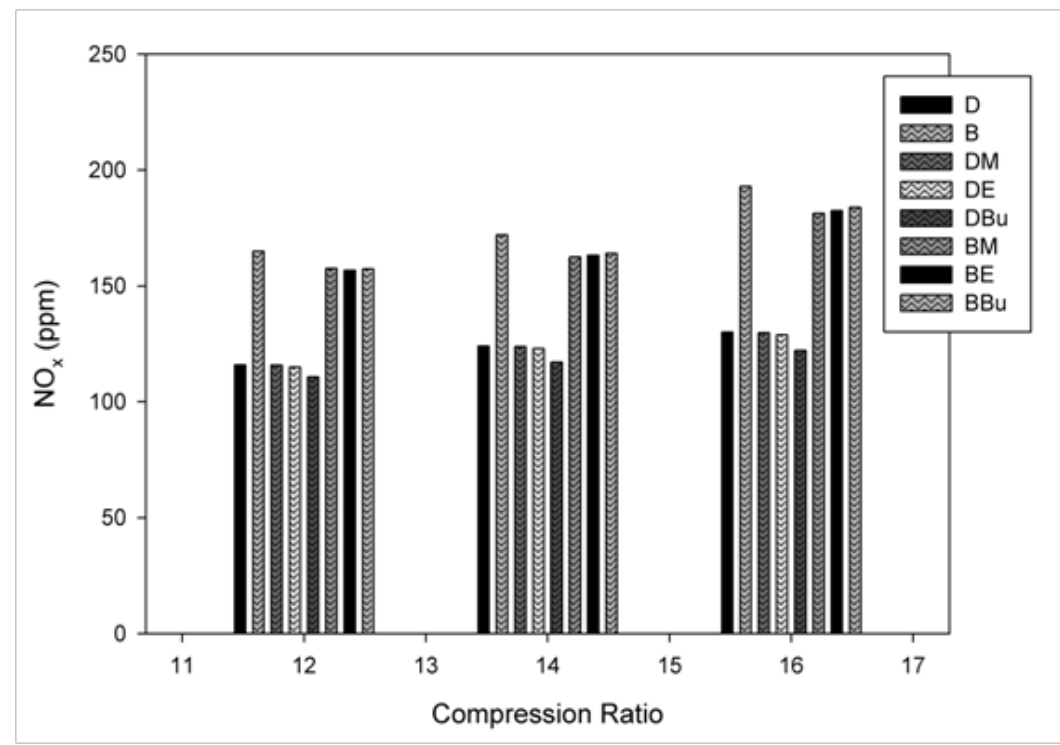

Figure 8: $\mathrm{NO}_{\mathrm{x}}$ values of test fuels

Alcohol addition to diesel fuel, improved CO emissions of diesel-alcohol blends due to extra oxygen content of alcohols compared to diesel fuel. Also, biodiesel-alcohol blends showed similar trend. The maximum decrement of $\mathrm{CO}$ emissions was occurred as 3,67\% for diesel-alcohol blends compared to diesel fuel when engine was fuelled with D95E5 fuel at 16:1 CR. Also maximum decrement of CO emissions was measured as 3,91\% for biodiesel-alcohol blends when engine was fuelled with B95Bu5 fuel compared to biodiesel fuel at 16:1 CR.

The experimental results revealed that blending diesel and biodiesel fuels with alcohols caused to increase of $\mathrm{CO}_{2}$ emissions. The maximum increment of $\mathrm{CO}_{2}$ emissions compared to diesel fuel was occurred as $8,97 \%$ when the engine fuelled with D95E5 fuel at 16:1 CR for diesel-alcohol blends. For biodiesel-alcohol blends, the maximum increment was observed with B95E5 fuel as 7,94\% compared to biodiesel at 16:1 CR. The main reason of these trends may be due to improved combustion of diesel-alcohol and biodiesel-alcohol blends [19].

According to experimental results, blending alcohols with diesel and biodiesel fuels resulted in improved $\mathrm{NO}_{\mathrm{x}}$ emissions which are one of the main drawbacks of compression ignition engines especially when the engine is fuelled with biodiesel fuel. $\mathrm{NO}_{\mathrm{x}}$ emissions were improved for all diesel-alcohol and biodiesel-alcohol blends compared to diesel fuel and biodiesel fuel. The maximum improvement of $\mathrm{NO}_{\mathrm{x}}$ emissions for diesel-alcohol blends was obtained as $6,40 \%$ compared to diesel fuel when the engine was fuelled with $\mathrm{D} 95 \mathrm{Bu} 5$ fuel at 16:1 CR. The maximum improvement of $\mathrm{NO}_{\mathrm{x}}$ emission for biodiesel-alcohol blends were observed when the engine was fuelled with B95M5 fuel as 6,01\% compared to diesel fuel at 16:1 CR. The main reason of NOx improvements may be due to high latent heat of evaporation of alcohols which shows a cooling effect and decreases the combustion temperature. $\mathrm{NO}_{\mathrm{x}}$ formation is directly related with combustion temperature $[20,21]$. 


\section{CONCLUSION}

In this study, performance and emission characteristics of alcohol blended fuel were evaluated. Fuel properties of the test fuels, performance and emission characteristics of the fuel at different compression ratios were studied and the following conclusions were obtained;

- BTHE and SFC values improved at higher compression ratios for all test fuels.

- Alcohol addition to diesel fuel slightly decreased BTHE and thus increased SFC.

- Alcohol addition to biodiesel fuel slightly improved BTHE and SFC values.

- Alcohol addition to both diesel and biodiesel fuels slightly improved $\mathrm{CO}$ emissions and caused a slight increment of $\mathrm{CO}_{2}$ emissions. Also, alcohol addition improved slightly $\mathrm{NOx}$ emissions for both diesel and biodiesel fuels.

\section{ACKNOWLEDGEMENTS}

The authors would like to thank the Cukurova University Scientific Research Project Coordination (FBA-2016-5510) for financial support to this project.

\section{REFERENCES}

[1] Ozcanli, M. (2015). Castor-oil methyl ester/butanol/diesel fuel blend as an alternative for compression ignition engines. Journal of Biotechnology, vol. 208, p. S32. 10.1016/j.jbiotec.2015.06.089

[2] Serin, H., Ozcanli, M., Gokce, M.K., and Tuccar, G. (2013). Biodiesel Production From Tea Seed (Camellia Sinensis) Oil and its Blends With Diesel Fuel. International Journal of Green Energy, vol. 10, no. 4, pp. 370-377. 10.1080/15435075.2012.655354

[3] Uludamar, E., Yıldızhan, Ş., Aydın, K., and Özcanlı, M. (2016). Vibration, noise and exhaust emissions analyses of an unmodified compression ignition engine fuelled with low sulphur diesel and biodiesel blends with hydrogen addition. International Journal of Hydrogen Energy, vol. 41, no. 26, pp. 11481-11490. 10.1016/j.ijhydene.2016.03.179

[4] Uludamar, E. et al. (2017). Evaluation of vibration characteristics of a hydroxyl (HHO) gas generator installed diesel engine fuelled with different diesel-biodiesel blends. International Journal of Hydrogen Energy, https://doi.org/10.1016/j.ijhydene.2017.01.192

[5] Ozcanli, M., Akar, M.A., Calik, A., and Serin, H. (2017). Using HHO (Hydroxy) and hydrogen enriched castor oil biodiesel in compression ignition engine. International Journal of Hydrogen Energy, 10.1016/j.ijhydene.2017.01.091

[6] Serin, H., Ozgur, C., Ozcanli, M., Aydin, K., and Ozgur, T. (2013). Preparation of fuels by cracking of different plastics and their blends with diesel fuel. Current Opinion in Biotechnology, vol. 24, p. S44. 10.1016/j.copbio.2013.05.097

[7] Tosun, E., Yilmaz, A.C., Ozcanli, M., and Aydin, K. (2014). Determination of effects of various alcohol additions into peanut methyl ester on performance and emission characteristics of a compression ignition engine. Fuel, vol. 126, pp. 38-43. 10.1016/j.fuel.2014.02.037

[8] Yasin, M.H.m., Mamat, R., Yusop, A.F., Rahim, R., Aziz, A., and Shah, L.A. (2013). Fuel Physical Characteristics of Biodiesel Blend Fuels with Alcohol as Additives. Procedia Engineering, vol. 53, pp. 701-706. 10.1016/j.proeng.2013.02.091

[9] Imran, A., Varman, M., Masjuki, H.H., and Kalam, M.A. (2013). Review on alcohol fumigation on diesel engine: A viable alternative dual fuel technology for satisfactory engine performance and reduction of environment concerning emission. Renewable and Sustainable Energy Reviews, vol. 26, pp. 739-751. 10.1016/j.rser.2013.05.070

[10] Datta Bharadwaz, Y., Govinda Rao, B., Dharma Rao, V., and Anusha, C. (2016). Improvement of biodiesel methanol blends performance in a variable compression ratio engine using response surface methodology. Alexandria Engineering Journal, vol. 55, no. 2, pp. 1201-1209. 10.1016/j.aej.2016.04.006

[11] Keskin, A., Yaşar, A., Reşitoğlu, İ., Akar, M.A., and Sugözü, İ. (2013). The Influence of Diesel Fuel-biodiesel-ethanol-butanol Blends on the Performance and Emission Characteristics of a Diesel Engine. Energy Sources, Part A: Recovery, Utilization, and Environmental Effects, vol. 35, no. 19, pp. 1873-1881. 10.1080/15567036.2010.529568

[12] Masum, B.M., Kalam, M.A., Masjuki, H.H., Palash, S.M., and Fattah, I.M.R. (2014). Performance and emission analysis of a multi cylinder gasoline engine operating at different alcohol-gasoline blends. RSC Advances, vol. 4, no. 53, pp. 27898-27904. $10.1039 / \mathrm{c} 4 \mathrm{ra} 04580 \mathrm{~g}$

[13] Akar, M.A. (2016). Performance and emission characteristics of compression ignition engine operating with false flax biodiesel and butanol blends. Advances in Mechanical Engineering, vol. 8, no. 2, pp. 1-7. 10.1177/1687814016632677

[14] Balki, M.K., Sayin, C., and Canakci, M. (2014). The effect of different alcohol fuels on the performance, emission and combustion characteristics of a gasoline engine. Fuel, vol. 115, pp. 901-906. 10.1016/j.fuel.2012.09.020

[15] Imdadul, H.K. et al. (2016). Higher alcohol-biodiesel-diesel blends: An approach for improving the performance, emission, and combustion of a light-duty diesel engine. Energy Conversion and Management, vol. 111, pp. 174-185. 10.1016/j.enconman.2015.12.066 
[16] Tsai, J.-H. et al. (2014). Emissions from a generator fueled by blends of diesel, biodiesel, acetone, and isopropyl alcohol: Analyses of emitted PM, particulate carbon, and PAHs. Science of The Total Environment, vol. 466, pp. 195-202. 10.1016/j. scitotenv.2013.07.025

[17] Lattimore, T., Herreros, J.M., Xu, H., and Shuai, S. (2016). Investigation of compression ratio and fuel effect on combustion and PM emissions in a DISI engine. Fuel, vol. 169, pp. 68-78. 10.1016/j.fuel.2015.10.044

[18] Bora, B.J. and Saha, U.K. (2016). Experimental evaluation of a rice bran biodiesel - biogas run dual fuel diesel engine at varying compression ratios. Renewable Energy, vol. 87, pp. 782-790. 10.1016/j.renene.2015.11.002

[19] Chavan, S.B., Kumbhar, R.R., Kumar, A., and Sharma, Y.C. (2015). Study of Biodiesel Blends on Emission and Performance Characterization of a Variable Compression Ratio Engine. Energy \& Fuels, vol. 29, no. 7, pp. 4393-4398. 10.1021/acs.energyfuels.5b00742

[20] Huang, Z. et al. (2005). Performance and Emissions of a Compression Ignition Engine Fueled with Diesel/Oxygenate Blends for Various Fuel Delivery Advance Angles. Energy \& Fuels, vol. 19, no. 2, pp. 403-410. 10.1021/ef049855d

[21] Sayin, C. and Gumus, M. (2011). Impact of compression ratio and injection parameters on the performance and emissions of a DI diesel engine fueled with biodiesel-blended diesel fuel. Applied Thermal Engineering, vol. 31, no. 16, pp. 3182-3188. 10.1016/j.applthermaleng.2011.05.044 